\title{
AN AUTORADIOGRAPHIC STUDY OF THE PROJECTIONS OF THE CENTRAL NUCLEUS OF THE MONKEY AMYGDALA ${ }^{1}$
}

\author{
J. L. PRICE* AND D. G. AMARAL $\neq^{2}$ \\ *Department of Anatomy and Neurobiology, Washington University, School of Medicine, St. Louis, Missouri 63110 and $\ddagger$ The Salk Institute, \\ San Diego, California 92138
}

\begin{abstract}
The efferent connections of the central nucleus of the monkey amygdala have been studied using the autoradiographic method for tracing axonal projections. Small injections of ${ }^{3} \mathrm{H}$-amino-acids which are largely confined to the central nucleus lead to the labeling of several brainstem nuclei as far caudally as the spinomedullary junction. Specifically, in the forebrain, the central nucleus projects heavily to the bed nucleus of the stria terminalis, the basal nucleus of Meynert, the nucleus of the horizontal limb of the diagonal band, and more lightly to the substantia innominata and the preoptic area. In the hypothalamus, label is found over the dorsomedial nucleus, the perifornical region, the lateral hypothalamus, the supramammillary area, and most heavily in the paramammillary nucleus. In the thalamus, all components of the nucleus centralis medialis and the nucleus reuniens receive fibers from the central nucleus and there is a light projection to the medial pulvinar nucleus. In the mesencephalon, there is heavy labeling dorsal to the substantia nigra and over the peripeduncular nucleus and lighter labeling within the substantia nigra pars compacta and the ventral tegmental area; the midbrain central gray is also labeled. More caudally, fibers from the central nucleus travel in the lateral tegmental reticular fields and contribute collaterals to the raphe nuclei, the cuneiform nucleus, and the central gray substance. Perhaps one of the heaviest terminal zones is the parabrachial region of the pons, both the lateral and the medial nuclei of which receive a prominent central nucleus projection. Only the ventral aspect of the adjacent locus coeruleus appears to receive a substantial input, but there is labeling also over the area of the nucleus subcoeruleus. Finally, there is heavy labeling around the dorsal motor nucleus of the vagus and over the parvocellular component of the nucleus of the solitary tract. A number of intra-amygdaloid connections between the basal and lateral nuclei of the amygdala and the central nucleus are also described. The present findings, taken together with recently reported widespread projections from the temporal association cortex to the amygdala, point out a potentially trisynaptic route between neocortical association regions and a variety of brainstem nuclei, many of which are related to autonomic function.
\end{abstract}

It has been known for some time that several components of the amygdaloid complex send fibers by way of the stria terminalis and the ventral amygdalofugal pathway to certain basal telencephalic and hypothalamic structures, such as the bed nucleus of the stria terminalis, the preoptic region, and the anterior hypothalamus (Fox, 1943; Nauta, 1961; Cowan et al., 1965). However, with the

${ }^{1}$ This work was supported in part by National Institutes of Health Grant NS-09518 to J. L. P. and Grants NS-10943 from the National Institutes of Health and DA-00259 from the Alcohol, Drug Abuse, and Mental Health Administration awarded to W. M. Cowan and was carried out while D. G. A. was in receipt of a National Institutes of Health postdoctoral fellowship (F32-NSO-5765). This work also was conducted in part by the Clayton Foundation for Research-California Division. D. G. A. is a Clayton Foundation Investigator.

${ }^{2}$ To whom correspondence should be addressed at The Salk Institute, P.O. Box 85800, San Diego, CA 92138. use of more sensitive techniques for tracing axonal connections, a more extensive subcortical distribution of amygdaloid fibers has been discovered (Heimer and Nauta, 1969; de Olmos, 1972; Krettek and Price, 1978). A number of recent studies in the rat, cat, and monkey (Hopkins, 1975; Hopkins and Holstege, 1978; Krettek and Price, 1978; Post and Mai, 1980; Schwaber et al., 1980) using both orthograde and retrograde mapping techniques have demonstrated a fairly pronounced projection of the central nucleus of the amygdala to such brainstem autonomic regions as the parabrachial nuclei and the nucleus of the solitary tract. These data are particularly interesting in light of the numerous autonomic responses that can be elicited upon electrical stimulation of the amygdala (Kaada, 1972) which include, among others, bradycardia, respiratory alterations, pupillary dilation, and micturition. 
As part of an ongoing study of the efferent connections of the amygdaloid nuclei in the monkey, we have been able to demonstrate extensive projections from the primate central nucleus not only to the basal forebrain, diencephalon, and midbrain but also to lower brainstem structures as far caudally as the spinomedullary junction.

\section{Materials and Methods}

Nine cynomolgus monkeys (Macaca fascicularis) were used in this study. The animals were anesthetized with ketamine $\mathrm{HCl}(8 \mathrm{mg} / \mathrm{kg}$, i.m.) followed by sodium pentobarbital ( $25 \mathrm{mg} / \mathrm{kg}$, i.p.) and mounted in a Kopf stereotaxic apparatus. Using aseptic procedures, the skull was exposed and a small burr hole was made at a site appropriate for the injection. Prior to injection of the isotope, an insulated tungsten electrode was lowered along the trajectory of the proposed injection, and single unit recordings were made at several levels. By defining certain electrophysiologically characteristic regions, such as the cortical surface, the lateral ventricle, and the cellrich zones of the amygdala and underlying entorhinal cortex, we were able to place the injections accurately even though there is substantial variability in the size of monkey brains.

When the appropriate coordinates had been determined, a single $100-\mathrm{nl}$ injection of a mixture of $\left[{ }^{3} \mathrm{H}\right]-$ proline and $\left[{ }^{3} \mathrm{H}\right]$ lysine (at a concentration of $50 \mu \mathrm{Ci} / \mu \mathrm{l}$ ) was pressure-injected through a glass pipette (tip diameter, approximately $20 \mu \mathrm{m}$ ). Animals were allowed to survive for 2 weeks and then were anesthetized deeply and perfused transcardially with $200 \mathrm{ml}$ of saline followed by $2000 \mathrm{ml}$ of a $0.1 \mathrm{M}$ phosphate-buffered $10 \%$ formalin solution. The brain was exposed, blocked on the stereotaxic apparatus, and returned to the same fixative for at least 1 week. Subsequently, brains were prepared either for paraffin or frozen sectioning and processed for autoradiographic localization of axonal connections (Cowan et al., 1972).

In seven monkeys, bilateral injections were made into the amygdala (aimed at different targets) so that 16 injections were available for analysis. Of these experiments, the injection into the right amygdala of animal DM28 was centered in the body of the central nucleus with very little involvement of any adjoining area. This case provides the best and most complete demonstration of the projections of the central nucleus and we shall give a rather complete description of this preparation. We examined all preparations by first tracing representative coronal sections with a projection device and then plotting the location of silver grains, as viewed with both dark-field and bright-field optics, on these plates.

In the course of our analysis, we often noted neuronal perikarya which, when viewed with dark-field illumination, contained bluish pink granules. As these inclusions were found most commonly in cells belonging to known catecholaminergic cell groups, such as the substantia nigra and the locus coeruleus, the particles are very probably neuromelanin granules. In fact, neuromelanin, and its ability to reduce diamine silver oxide, has been used as a marker for catecholaminergic cell groups in monkeys (German and Bowden, 1975) and humans (Bogerts, 1981). Since projections from the central nucleus were found to most of the areas with neuromelanincontaining cells, we have plotted their location (as triangles) on Figure 1 along with the distribution of autoradiographic label.

\section{Results}

We shall first describe experiment DM28R as representative of the projections of the central nucleus. The injection site, projections, and terminal fields are shown diagrammatically in Figure 1 . We shall then discuss several injections which involved one or more of the areas surrounding the central nucleus as controls for the specificity of the projection from the central nucleus, and finally, we shall describe certain intra-amygdaloid projections with direct relevance to the connectivity of the central nucleus.

\section{DM28R}

\section{Injection site}

The injection in DM28R is centered just ventromedial to the midpoint of the central nucleus (Figs. 1, $B$ and $C$, and $2, A$ and $B$ ), and although the medial part of the nucleus is most heavily labeled, all portions of the nucleus except for the lateral and dorsal edges are involved by the injection. The dorsal, magnocellular regions of the basal accessory and basolateral nuclei also are slightly involved by the injection and perhaps also the deepest (most lateral) aspect of the medial nucleus. However, in all of these cases, this involvement would appear to be minimal since the substantial extra-amygdaloid projections of the basolateral and basal accessory nuclei (e.g., to the subiculum), which are labeled in other experiments in this series, are not labeled in DM28R. Moreover, we have found that the projection of the medial nucleus to the diencephalon is substantially different from that seen from the central nucleus and there are no projections from the medial nucleus which extend caudal to the posterior hypothalamus. No structures outside of the amygdaloid complex are involved either by diffusion from the injection itself or along the course of the injection pipette.

\section{Course of the fiber projection}

Following the relatively long survival time used in these experiments, the fiber pathways leading away from the injection sites are very well labeled. In case DM28R, as might be expected, most of the fibers travel via either the ventral amygdalofugal pathway or the stria terminalis in their course to the basal forebrain, diencephalon, and brainstem. However, we were somewhat surprised both by the caudal extent of the ventral amygdalofugal pathway and by a complex and almost continuous system of fibers which interconnects the ventral pathway with the stria terminalis rostrally and the dorsal and ventral components of the stria terminalis caudally.

The ventral amygdalofugal pathway is labeled over a very long anteroposterior distance, extending from the level of the anterior amygdaloid area rostrally to the substantia nigra caudally. At rostral levels, it is a broad fiber system which sweeps through the substantia innominata to join with fibers that have traveled through the stria terminalis and enter the preoptic area and the 

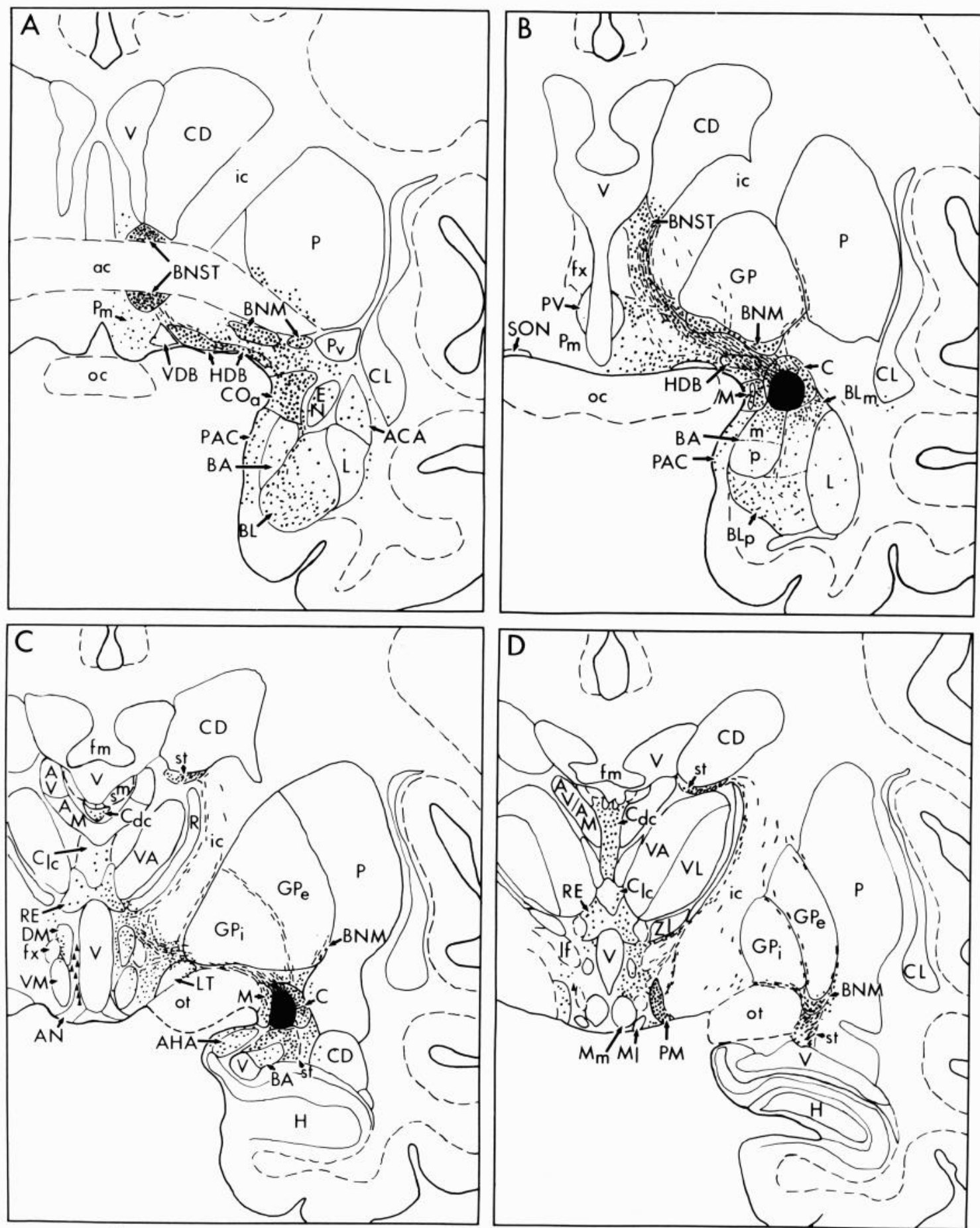

Figure $1 .^{3}$ A series of coronal sections at representative levels through the forebrain and brainstem to illustrate the distribution of autoradiographic silver grains in experiment DM28R. Dots represent terminal fields or axons cut transversely, while slashes represent longitudinally oriented labeled axons. In certain panels, such as $E$ and $F$, neuromelanin-containing cells are plotted on the left side of the panels as triangles. The sections are organized from rostral $(A)$ to caudal $(L)$.

\footnotetext{
${ }^{3}$ The abbreviations used on the figures are: ac, anterior commissure; ACA, amygdaloclaustral area; AHA, amygdalohippocampal area; AM, anteromedial nucleus (thalamus); $\mathrm{AN}$, arcuate nucleus (hypothalamus); $\mathrm{AV}$, anteroventral nucleus (thalamus); $\mathrm{BA}$, basal accessory nucleus (amygdala); $\mathrm{BA}_{\mathrm{m}}$, basal accessory nucleus pars magnocellularis (amygdala); $\mathrm{BA}_{\mathrm{p}}$, basal accessory nucleus pars parvocellularis (amygdala); bc, brachium conjunctivum; $\mathrm{BL}$, basolateral nucleus (amygdala); $\mathrm{BL}_{\mathrm{m}}$, basolateral nucleus pars magnocellularis (amygdala); $\mathrm{BL}_{\mathrm{p}}$, basolateral nucleus pars parvocellularis (amygdala); BNM, basal nucleus of Meynert; BNST, bed nucleus of the stria terminalis; bp, brachium pontis;
}

$\mathrm{C}$, central nucleus (amygdala); $\mathrm{CBL}$, cerebellum; $\mathrm{CD}$, caudate nucleus; $\mathrm{C}_{\mathrm{dc}}$, nucleus centralis pars densocellularis (thalamus); $\mathrm{CG}$, central gray; $\mathrm{C}_{\mathrm{if}}$, nucleus centralis inferior (thalamus); $\mathrm{C}_{\mathrm{im}}$, nucleus centralis intermedius (thalamus); $\mathrm{CL}$, claustrum; $\mathrm{C}_{1}$, nucleus centralis lateralis (thalamus); $\mathrm{C}_{\mathrm{lc}}$, nucleus centralis pars latocellularis (thalamus); $\mathrm{CM}$, nucleus centralis medialis (thalamus); $\mathrm{CO}_{\mathrm{a}}$, anterior cortical nucleus (amygdala); $\mathrm{CO}_{\mathrm{p}}$, posterior cortical nucleus (amygdala); $\mathrm{cp}$, cerebral peduncle; $\mathrm{C}_{s}$, nucleus centralis superior (thalamus); CS, central superior raphe nucleus; DK, nucleus of Darkschewitsch; DM, dorsomedial nucleus (hypothalamus); DMN, dorsal motor nucleus of the vagus nerve; DR, 

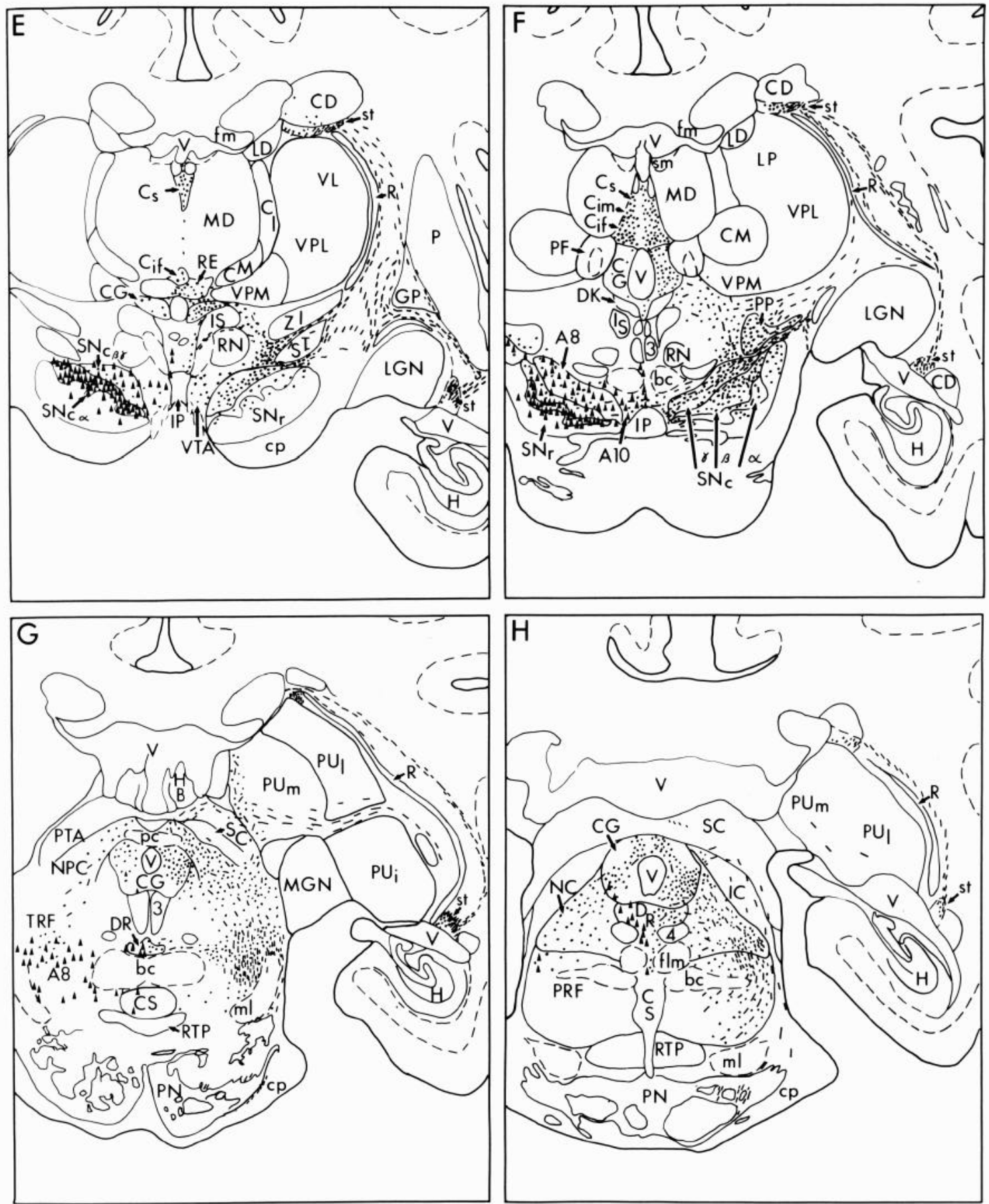

Figure 1. Continued.

dorsal raphe nucleus; EC, entorhinal cortex; EN, endopiriform nucleus; flm, medial longitudinal fasciculus; fm, fimbria; fx, fornix; GP, globus pallidus; $\mathrm{GP}_{e}$, globus pallidus (external); $\mathrm{GP}_{\mathrm{i}}$, globus pallidus (internal); $\mathrm{H}$, hippocampal formation; $\mathrm{HB}$, habenular nuclei; HDB, horizontal limb of the nucleus of the diagonal band; IC, inferior colliculus; ic, internal capsule; IO, inferior olive; IP, interpeduncular nucleus; IS, interstitial nucleus; $\mathrm{L}$, lateral nucleus (amygdala); $\mathrm{LC}_{\mathrm{d}}$, nucleus locus coeruleus pars dorsalis; $\mathrm{LCN}$, lateral cuneate nucleus; $\mathrm{LC}_{\mathrm{v}}$, nucleus locus coeruleus pars ventralis; $\mathrm{LD}$, laterodorsal nucleus (thalamus); lf, lenticular fasciculus; LGN, lateral geniculate nucleus (thalamus); LH, lateral hypothalamus; LP, lateroposterior nucleus (thalamus); LR, lateral reticular nucleus; LT, lateral tuberal nucleus (hypothalamus); M, medial nucleus (amygdala); MD, mediodorsal nucleus (thalamus); MGN, medial geniculate nucleus (thalamus); $\mathbf{M}_{1}$, lateral mammillary nucleus; $\mathrm{ml}$, medial lemniscus; $\mathrm{M}_{\mathrm{m}}$, medial mammillary nucleus; $\mathrm{NC}$, nucleus cuneiformis; NPC, nucleus of the posterior commissure; NST, nucleus of the solitary tract; $\mathrm{NST}_{\mathrm{p}}$, nucleus of the solitary tract pars parvocellularis; oc, optic chiasm; ot, optic tract; P, putamen; PAC, periamygdaloid cortex; $\mathrm{Pb}_{1}$, lateral parabrachial nucleus; $\mathrm{Pb}_{\mathrm{m}}$, medial parabrachial nucleus; pc, posterior commissure; PF, parafascicular nucleus; $\mathrm{PH}$, nucleus prepositus hypoglossi; $\mathrm{P}_{\mathrm{m}}$, medial preoptic nucleus; $\mathrm{PM}$, paramammillary nucleus; $\mathrm{PN}$, pontine nuclei; $\mathrm{PP}$, peripeduncular nucleus; PR, paramedian reticular nucleus; PRF, pontine reticular formation; PS, parasolitary nucleus; pt, pyramidal tract; PTA, pretectal area; $\mathrm{PU}$, pulvinar nucleus; $\mathrm{PU}_{\mathrm{i}}$, pulvinar nucleus pars inferior; $\mathrm{PU}_{1}$, pulvinar nucleus pars lateralis; $\mathrm{PU}_{\mathrm{m}}$, pulvinar nucleus pars medialis; $\mathrm{PV}$, periventricular nucleus (hypothalamus); $\mathrm{P}_{\mathrm{v}}$, ventral putamen; $\mathrm{R}$, nucleus reticularis (thalamus); RE, nucleus reuniens (thalamus); RF, reticular formation; $\mathrm{RM}$, nucleus raphe magnus; $\mathrm{RN}$, red nucleus; $\mathrm{RP}$, nucleus raphe pallidus; RTP, nucleus reticularis tegmenti pontis; SC, 


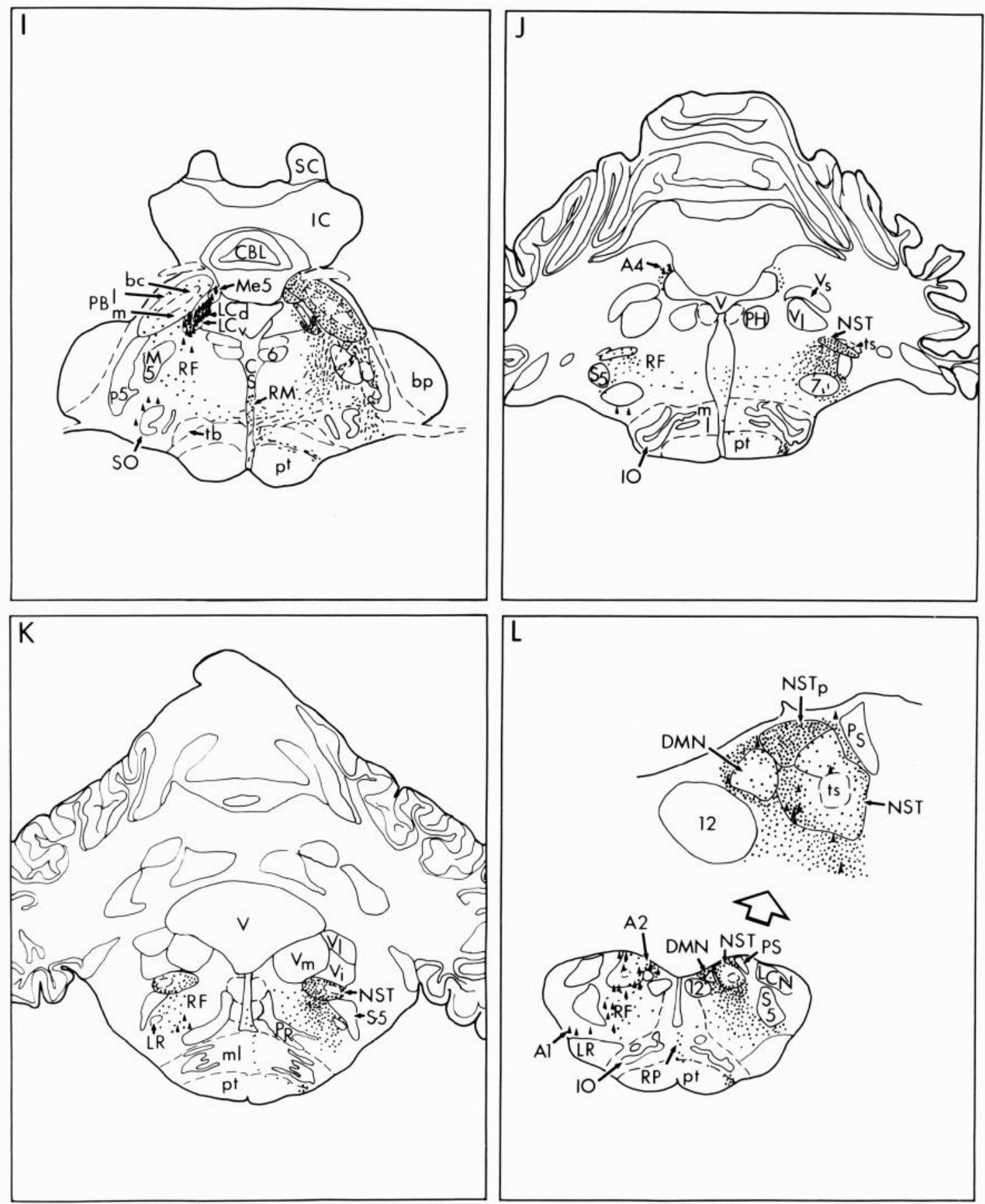

Figure 1. Continued.

superior colliculus; $\mathrm{SI}$, substantia innominata; $\mathrm{sm}$, stria medullaris; $\mathrm{SN}_{\mathrm{c}}$, substantia nigra pars compacta; $\mathrm{SN}_{\mathrm{r}}$, substantia nigra pars reticulata; SO, superior olive; SON, supraoptic nucleus; ST, subthalamic nucleus; st, stria terminalis; tb, trapezoid body; TRF, tegmental reticular field; ts, solitary tract; V, ventricle; VA, nucleus ventralis anterior (thalamus); VDB, vertical limb of the nucleus of the diagonal band; $V_{i}$, inferior vestibular nucleus; $\mathrm{VL}$, nucleus ventralis lateralis (thalamus); $\mathrm{V}_{1}$, lateral vestibular nucleus; VM, ventromedial nucleus (hypothalamus); $V_{m}$, medial vestibular nucleus; VPL, nucleus ventralis posterolateralis (thalamus); VPM, nucleus ventralis posteromedialis (thalamus); $\mathrm{V}_{\mathrm{s}}$, superior vestibular nucleus; VTA, ventral tegmental area; ZI, zona incerta; 3 , oculomotor nucleus; 4 , trochlear nucleus; 6 , abducens nucleus; 7 , facial nucleus; 12 , hypoglossal nucleus; M5, motor nucleus of the trigeminal nerve; Me5, mesencephalic nucleus of the trigeminal nerve; $\mathrm{P} 5$, principal nucleus of the trigeminal nerve; $\mathbf{S} 5$, spinal nucleus of the trigeminal nerve.

Figure 2. $A$ and $B$, Bright-field and dark-field photomicrographs of the same coronal section which demonstrate the projection of the central nucleus, via the ventral amygdalofugal pathway, to the basal nucleus of Meynert, the nucleus of the horizontal limb of the diagonal band, and the bed nucleus of the stria terminalis. This and all subsequent autoradiographs are taken from experiment DM28R. Magnification $\times 9$. $C$ and $D$, Bright-field and dark-field photomicrographs of the same coronal section through the hypothalamus at the level of the ventromedial nucleus. Fibers enter the hypothalamus from its lateral aspect (open arrow) and fan out dorsally to innervate the lateral hypothalamus, the perifornical area, and the dorsomedial nucleus. Fibers continue dorsally to end in the ventrolateral quadrant of nucleus reuniens of the thalamus (solid arrow). Magnification $\times 19$. 
The Journal of Neuroscience

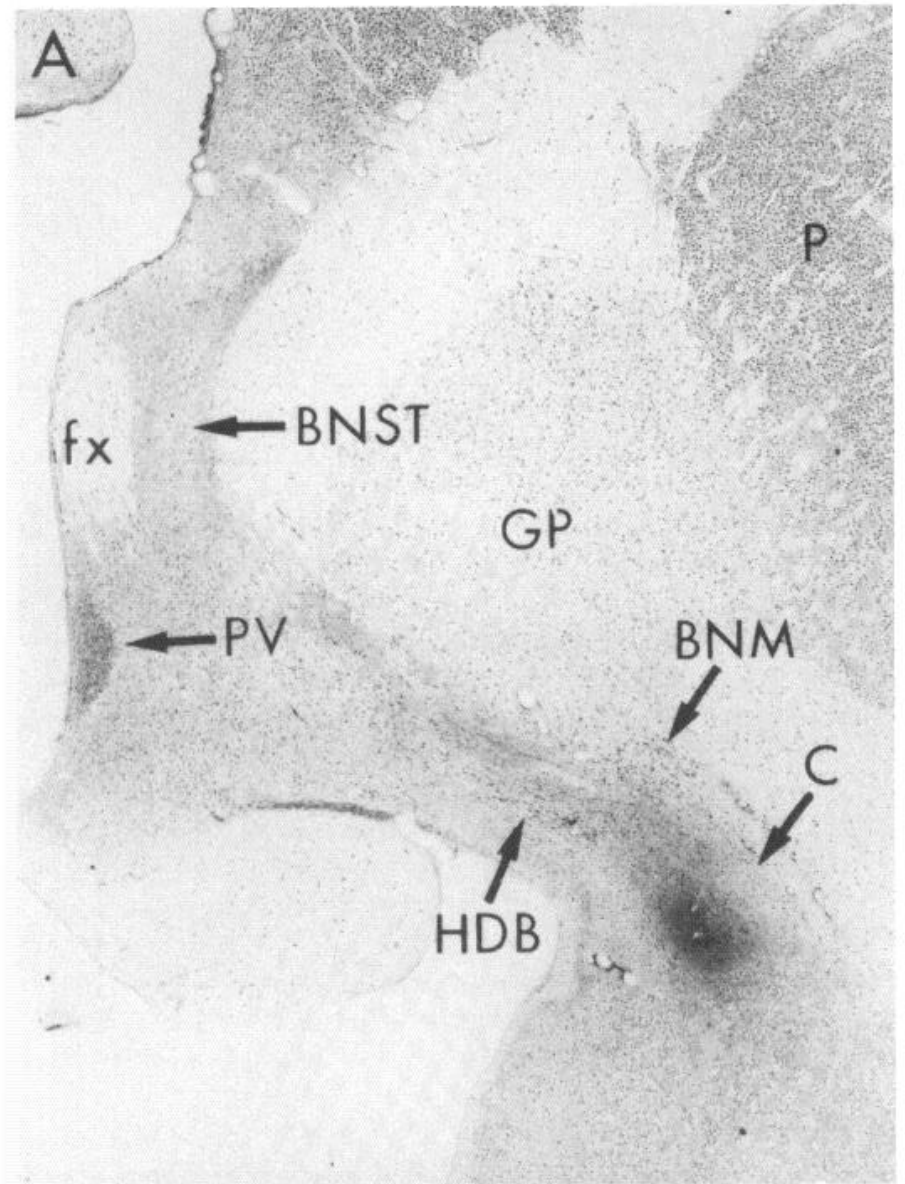

C

RE

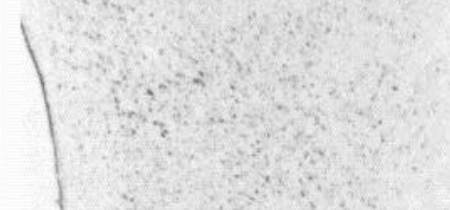

DM

GP

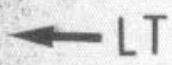

B
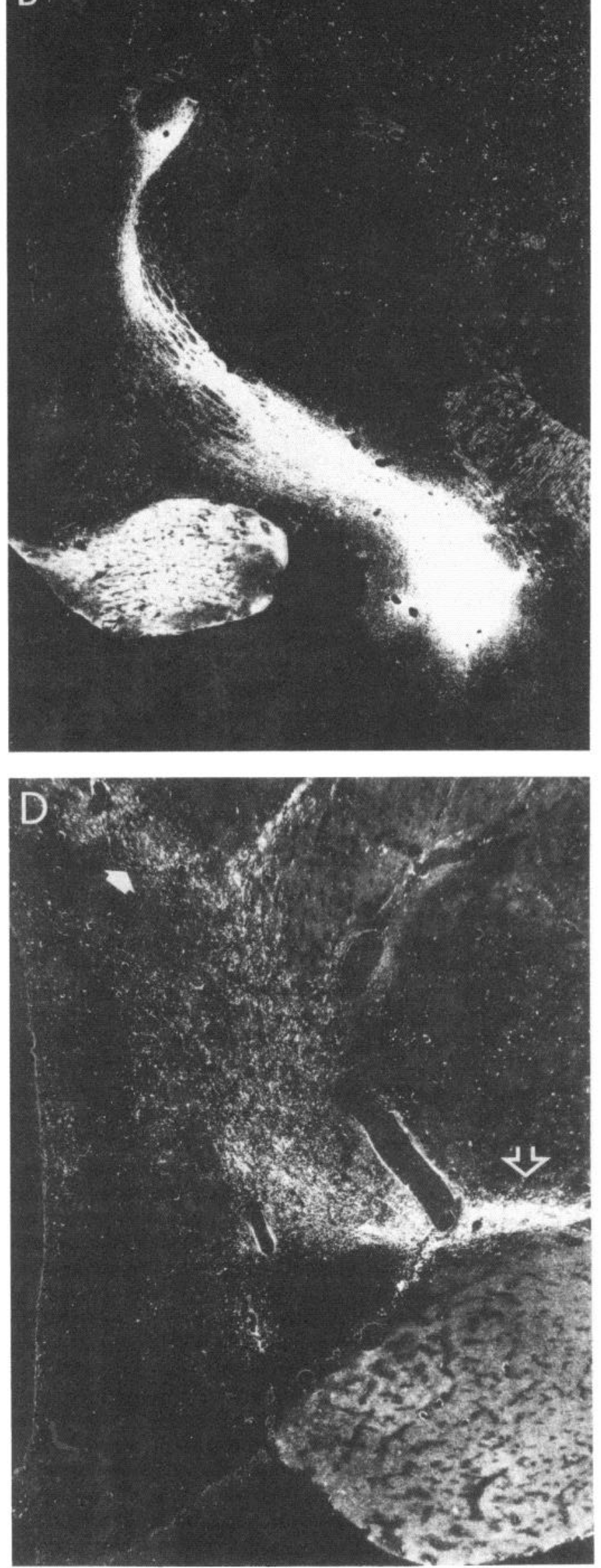
lateral hypothalamus (Figs. $1 B$ and $2 B$ ). Further caudally, the ventral pathway becomes compressed into a thin sheet which passes medially into the hypothalamus between the optic tract and the internal segment of the globus pallidus (Fig. 1, C and D). This sublenticular portion of the ventral pathway appears to carry most of the fibers which will terminate in the caudal hypothalamus and brainstem. At its caudal extent, the ventral pathway passes dorsal to the lateral geniculate nucleus and through the internal capsule to enter the ventral midbrain through the peripeduncular nucleus at the lateral edge of the substantia nigra (Figs. $1, E$ and $F$, and 3 , $A$ and $B$ ).

A number of fibers also leave the caudal aspect of the central nucleus and collect into the stria terminalis (Fig. $1, C$ and $D$ ). These fibers run through the entire length of the stria terminalis, and at its rostral extent, they sweep ventrally through the bed nucleus of the stria terminalis and mix inextricably with fibers from the rostral part of the ventral pathway.

In addition to these well known amygdalofugal pathways, at all anteroposterior levels of the trajectory of the stria terminalis, fibers are found passing between the dorsal and ventral parts of the stria as well as between the dorsal part of the stria and the ventral amygdalofugal pathway (Figs. 1, $C$ to $H$, and $3, B$ and $C$ ). These fibers run through the fiber laminae between the internal and external segments of the globus pallidus and the putamen as well as through the internal capsule immediately lateral to the reticular nucleus of the thalamus. At caudal levels (Figs. $1 G$ and $3 C$ ), some of these fibers appear to traverse the lateral aspect of the pulvinar nuclei in the corticotectal tract to innervate the medial pulvinar nucleus.

These observations lead us to the conclusion that the ventral amygdalofugal pathway and the stria terminalis are not separate pathways but rather that they are major components of a complex, continuous sheet of fibers which passes around, but also penetrates through, the internal capsule to reach the basal forebrain, diencephalon, and midbrain. Because of the intermixing of the components of this pathway, it is not possible to determine, in the present material, the trajectory of fibers to any particular terminal field.

Caudal to the substantia nigra, labeled fibers collect in a rather diffuse bundle in the dorsolateral portion of the tegmental reticular formation (Figs. $1 G$ and $3, C$ and $D$ ). These fibers continue through the reticular formation to the parabrachial region and further caudally throughout the medulla. Fibers appear to peel off from the main bundle and cross the midline all along the pontine and medullary course of the projection. A small number of fibers pass ventrally at caudal levels and travel at the ventrolateral aspect of the pyramidal tract (Fig. 1, $I$ to
$L$ ). We were not able to trace these fibers caudal to the spinomedullary junction.

\section{Areas of termination}

Basal forebrain. Two closely related, magnocellular nuclei in the basal forebrain, the basal nucleus of Meynert and the horizontal limb of the diagonal band, are both heavily labeled by axonal transport throughout their rostrocaudal extent (Fig. 1, $A$ to $D$ ). The label in the diagonal band region extends up to the junction between the vertical and horizontal limbs, but there is relatively little label associated with either the vertical limb of the diagonal band or with the adjacent septal nuclei. In the basal nucleus of Meynert, label is found not only over the clusters of larger cells immediately dorsal and medial to the amygdala, which constitute the bulk of the nucleus, but also over the smaller, more scattered groups of cells which extend around the anterior commissure and between the subdivisions of the globus pallidus and the putamen. Somewhat lighter label is also found in the caudal part of the substantia innominata and, further rostrally, in the olfactory tubercle. In the tubercle, label is concentrated in and around the cellular layer and, in some cases, appears to be related to the islands of Calleja, especially the insula magna at the medial edge of the nucleus accumbens, although the nucleus accumbens itself is not labeled.

As expected, the bed nucleus of the stria terminalis is heavily labeled (Figs. 1, $A$ and $B$, and $2, A$ and $B$ ) especially in its lateral part. However, unlike the situation in the rat (Krettek and Price, 1978), label is not restricted to the lateral edge but rather extends into both medial and precommissural parts. Furthermore, there is a significant, though lower, amount of label located ventral to the bed nucleus in the preoptic area; this more diffuse labeling pattern extends back into the anterior hypothalamus.

Hypothalamus. As in the rat and cat, the lateral hypothalamic area is innervated densely by labeled fibers which travel, for the most part, through the ventral amygdalofugal pathway and sweep into the lateral aspect of the hypothalamus along its entire rostrocaudal extent (Fig. 1, $C$ and $D$ ). However, in DM28R, the label also extends medially, as far as the lateral border of the ventromedial nucleus, and dorsally, into the dorsomedial nucleus and dorsal hypothalamic area. One striking feature of the distribution of label to the lateral hypothalamic region is the almost complete absence of label to the lateral tuberal nucleus (Figs. $1 C$ and $2, B$ and $C$ ) which is in sharp contrast to the heavily labeled area around it. It is of interest that, in experiments with injections into the basolateral amygdaloid nucleus, projections to the lateral tuberal nucleus are heavily labeled. A number of catecholaminergic cells which do not appear

Figure 3. $A$ and $B$, Bright-field and dark-field photomicrographs of adjacent coronal sections from the mesencephalon and caudal thalamus. Fibers arising from the stria terminalis course medially over the lateral geniculate nucleus and through the internal capsule to enter the substantia nigra pars compacta. Note also that some fibers (solid arrows) appear to travel between the dorsal and ventral components of the stria terminalis. Magnification $\times 8$. C, A dark-field autoradiograph taken at a midmesencephalic level. Fibers travel between the dorsal and ventral components of the stria terminalis (solid arrows) and a small contingent travels medially in the corticotectal tract (triangles) to end in the medial portion of the medial pulvinar at a level slightly rostral to this section. Descending fibers of the central nucleus can be seen in the tegmental reticular fields at this level (open arrow). Magnification $\times 10.5$. D, Dark-field autoradiograph of the central nucleus projection to the mesencephalic central gray substance. At this level, grains are distributed primarily to a ventrolateral (large arrow) and a smaller dorsomedial area (smaller arrows). Magnification $\times 13$. 

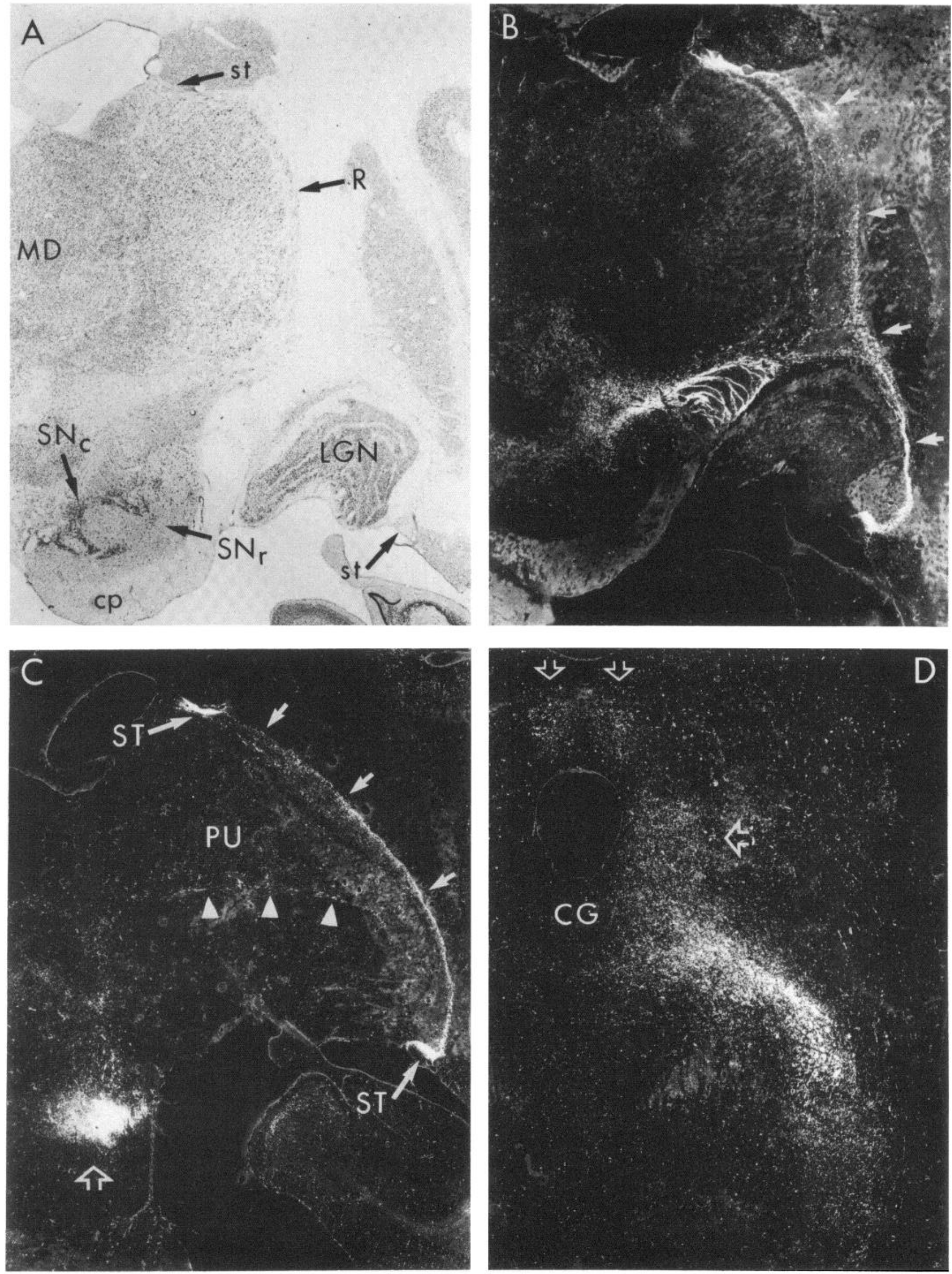
to receive a central nucleus projection are located within the periventricular region of the hypothalamus and the rostral part of the arcuate nucleus (A12 and A14, see Fig. $1 C)$.

In the caudal third of the hypothalamus, the label in the lateral hypothalamic area is continuous with heavier label in the paramammillary nucleus (Fig. 1D). There is also transported label among the cells of the tuberomammillary nucleus and within the supramammillary region, although the medial and lateral mammillary nuclei are completely unlabeled.

Thalamus. The most prominent concentration of labeled axons in the thalamus is in the midline nuclei between the dorsal and ventral parts of the third ventricle (Fig. $1, D$ to $F$ ). All of the midline subdivisions of the nucleus centralis recognized by Olszewski (1952) are labeled bilaterally. The heaviest concentration of label is located in the caudal part of the midline thalamus where the superior, intermediate, and inferior subdivisions of the nucleus centralis come together to form a wide band between the mediodorsal nuclei (Fig. $1 F$ ). Surprisingly, there is little or no label in the paraventricular nucleus which resides just ventral to the third ventricle in close approximation to the nucleus centralis. The midline nucleus reuniens is also labeled with the greatest density of grains located over its ventrolateral aspect.

In the caudal thalamus, there is a patch of label which is restricted to the medial edge of the medial pulvinar nucleus. Labeled fibers appear to reach this area through the corticotectal tract from the white matter lateral to the reticular nucleus of the thalamus (Figs. $1 G$ and $3 C$ ). Some fibers in this bundle appear to continue medially to enter the midbrain, while others turn dorsally to terminate along the medial edge of the pulvinar, adjacent to the caudal pole of the mediodorsal nucleus. We saw no labeled fibers entering the mediodorsal nucleus in this experiment, although projections are found in other brains in which the injections involved the lateral, basolateral, or basal accessory nuclei.

Midbrain. In the midbrain, and in more caudal parts of the brainstem, the transported label is distributed bilaterally. While the pattern of labeling is, with a few exceptions, similar on both sides, the density of grains is substantially lighter on the contralateral side. Labeled fibers enter the midbrain both as a caudal extension of those fibers which entered the lateral hypothalamus at more rostral levels and through a caudal component of the ventral amygdalofugal pathway which travels around the lateral geniculate nucleus and pierces through the internal capsule (Figs. $1 E$ and $3, A$ and $B$ ). A portion of this pathway apparently arises from those fibers which pass between the dorsal and ventral parts of the stria terminalis. As these laterally derived fibers travel medially, they pass around and, in some cases, through the subthalamic nucleus, but they do not appear to terminate there. In contrast to this, the peripeduncular nucleus, which also lies within the path of the amygdalofugal fibers, is heavily labeled.
The major targets for labeled axons in the ventral midbrain are the substantia nigra and the ventral tegmental area (Figs. $1, E$ and $F$, and $3, A$ and $B$ ). Label is densest in the lateral and dorsal parts of Olszewski and Baxter's (1954) laminae $\beta$ and $\gamma$ of the substantia nigra pars compacta and much lighter in the $\alpha$ lamina (which is the largest component of the A9 group of dopaminergic cells; Felten et al., 1974; Garver and Sladek, 1975). Apart from the medial edge of the $\alpha$ lamina, which is almost free of label, the transported label follows closely the distribution of the neuromelanin-containing cells of the A8, A9, and A10 cell groups. Fibers cross the midline above the interpeduncular nucleus to provide a lighter projection to the same areas of the contralateral side.

Caudal to the substantia nigra, densely labeled fibers collect in a bundle which runs caudally in the lateral tegmental fields (Figs. $1 G$ and $3 C$ ). Fibers leave this pathway and pass dorsomedially into the mesencephalic central gray and adjacent structures (Fig. $3 D$ ). The nucleus of the posterior commissure and, more caudally, the nucleus cuneiformis are traversed by these fibers and both are heavily labeled (Fig. $1 G$ ). In the rostral part of the central gray, the label is relatively diffuse throughout. However, further caudally grains are concentrated in the ventrolateral and dorsomedial sectors of the central gray, leaving the ventromedial portion and a sharply delimited dorsolateral area more or less free of label (Figs. $1 \mathrm{H}$ and $3 D$ ).

Labeled axons also are found throughout the dorsal raphe nucleus. However, unlike the label in the central gray and the areas lateral to it, the label in the dorsal raphe is strictly unilateral.

In addition to the neuromelanin-containing cells of the substantia nigra and ventral tegmental area, there are also a number of catecholaminergic cells found in the lateral tegmental reticular field, many of which are located among the very densest concentration of transported label (Fig. 1, $G$ and $H$ ); there are also a few neuromelanin-containing cells within the dorsal raphe nucleus and the central gray. In all but a few cases, the neuromelanin-containing cells lie among or in close proximity to labeled axons from the central nucleus.

Pons and medulla. Caudal to the lateral tegmental fields, heavily labeled fascicles of axons continue into the reticular formation, in which they run as far as the caudal part of the medulla. Just caudal to the midbrain, fibers pass dorsally from the main bundle and around and through the motor nucleus of the fifth nerve (apparently without terminating in it) to ramify extensively in both the medial and lateral parabrachial nuclei and adjacent areas (Figs. 2I, and $4, A$ and $B$ ). The caudal part of the mesencephalic nucleus of the fifth nerve is also labeled at this level. Strikingly, label is not found over the densely cellular dorsal part of the locus coeruleus or in the mesencephalic tract of the fifth nerve immediately lateral to it (Fig. 4, $A$ and $B$ ), but light label is found medial to this part of the nucleus and over the ventral part of the locus coeruleus as well as among the scattered pigmented

Figure 4. $A$ and $B$, Bright-field and dark-field photomicrographs of the same section in the pons. Note the heavy terminal labeling of the parabrachial nuclei, the ventral locus coeruleus, and the subcoerulear region. Fibers which continue to descend are located just medial to the motor nucleus of the trigeminal nerve. Magnification $\times 13$. $C$ and $D$, Bright-field and dark-field photomicrographs of the same coronal section from the medulla at a level through the rostral third of the solitary complex. Note the heavy terminal labeling primarily localized to the parvocellular portion of the nucleus of the solitary tract. Magnification $\times$ 12.25 . 

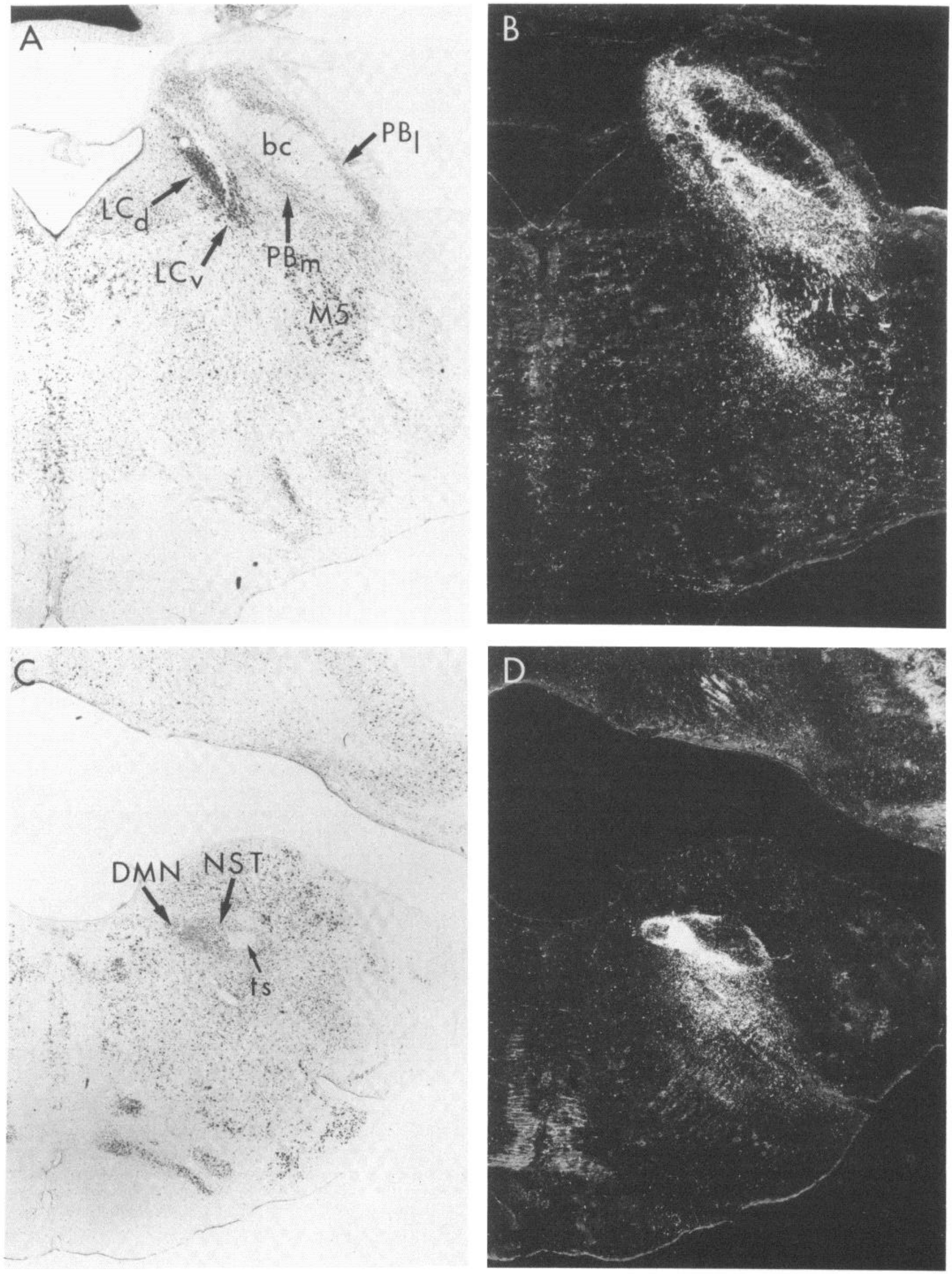
cells of the subcoerulear region; there is also light label over the most lateral aspect of the central gray at this level.

Ventrally, labeled fibers pass around the fascicles of the motor root of the fifth nerve and through the medial part of the principal sensory nucleus. Many of these fibers appear to ramify among the neuromelanin-containing cells of the A5 catecholaminergic cell group which is lateral and caudal to the superior olivary complex. Other fibers sweep medially to the nucleus raphe magnus where many of them cross to innervate the contralateral side.

Caudal to the parabrachial area, light label is seen over the A4 catecholaminergic cells which are located dorsolateral to the fourth ventricle (Fig. $1 J$ ). The heaviest label just caudal to this level is in the reticular formation and the nucleus of the solitary tract (Fig. $1 K$ ). At rostral levels of the nucleus, all subdivisions appear to be labeled, except for a small cluster of cells at the ventromedial edge of the solitary tract. At more caudal levels, the zone of sparse label near the tract expands substantially so that label within the nucleus is concentrated primarily in the dorsal, parvocellular portion and over a rim of cells which surround but are somewhat separated from the solitary tract (Figs. $1 L$ and $4, C$ and $D$ ). We are able to distinguish several subdivisions of the nucleus of the solitary tract on cytoarchitectonic grounds (Fig. $1 L$ ), but these do not appear to correspond to the medial and lateral subdivisions of Beckstead and Norgren (1979). In fact, both their medial and lateral subdivisions are labeled, in part, by fibers from the central nucleus.

The dorsal motor nucleus of the vagus, located just medial to the nucleus of the solitary tract, is surrounded by labeled fibers, but the neuropil of the nucleus contains substantially less label. The neuromelanin-containing cells of the catecholaminergic cell group A2 are also situated around the dorsal motor nucleus of the vagus (Fig. $1 L$ ) and in the medial edge of the nucleus of the solitary tract; both of these areas receive a particularly prominent investiture of labeled fibers.

The reticular formation ventral to the nucleus of the solitary tract also receives a fairly dense projection, including the area around the nucleus ambiguus which, in the rat and cat, has been reported to contain cells which project into the cardiac branches of the vagus nerve (Nosaka et al., 1979; Geis and Wurster, 1980). Labeled fibers also extend further ventrally to innervate a region in the ventrolateral medullary reticular formation, which contains cells of the A1 catecholaminergic cell group, and medially to supply the raphe pallidus. As at more rostral levels, a few fibers cross to innervate the same areas on the opposite side.

Finally, in both the pons and the medulla, a few fiber bundles pass into the ventral part of the brainstem and run caudally with the corticospinal fibers. These labeled fibers are found, at pontine levels, among the pontine nuclei and then collect, more caudally, to descend along the dorsolateral edge of the pyramidal tract to the spinomedullary border. Fibers appear to be added to this pathway from the main descending bundle of fibers at all levels throughout the hindbrain. We were not able to relate these bundles of axons to any distinct group of cells, but their location in the medulla corresponds to the more lateral serotonergic cells of the raphe pallidus and magnus (B1 to B3; Schofield and Everitt, 1981). We were not able to detect any labeled fibers caudal to the spinomedullary border.

\section{$D M 18 R$ and $D M 22 R$}

There are two brains in our series of preparations which had injections located immediately adjacent to the dorsomedial aspect of the central nucleus. In case DM18R (Fig. 5A), the injection involved the medial amygdaloid nucleus, the dorsomedial tip of the central nucleus, the substantia innominata, and the lateral aspect of the nucleus of the horizontal limb of the diagonal band. The injection of DM22R (Fig. $5 B$ ) was somewhat more caudal and involved the medial amygdaloid nucleus as well as the substantia innominata.

There are a number of projections which distinguish these injections from that of DM28R. For example, in DM22R, there is label in the hippocampal formation, the ventromedial hypothalamic nucleus, the lateral habenular nucleus, and the posterior mediodorsal nucleus of the thalamus; none of these areas are labeled in DM28R. However, there is also label in both DM22R and DM18R in all of the basal forebrain, diencephalic, and mesencephalic structures which are labeled in DM28R. Caudal to the mesencephalon, though, the density of labeled fibers rapidly decreases and we have not found a projection to either the parabrachial nuclei or to any of the more caudal structures which are labeled from the central nucleus in DM28R. Since Hopkins (1975) and Schwaber et al. (1980) were able to retrogradely fill cells of the substantia innominata with horseradish peroxidase injected into the caudal brainstem of the monkey and rabbit, we expected to see some orthograde labeling of this region from the injections in DM18R and DM22R. However, we suspect that both of these injections were situated too far ventrolaterally to involve a sufficient number of caudally projecting substantia innominata cells. It is also of interest to note that no other nucleus of the amygdaloid complex contained retrogradely filled cells in the studies of Hopkins (1975) or Schwaber et al.
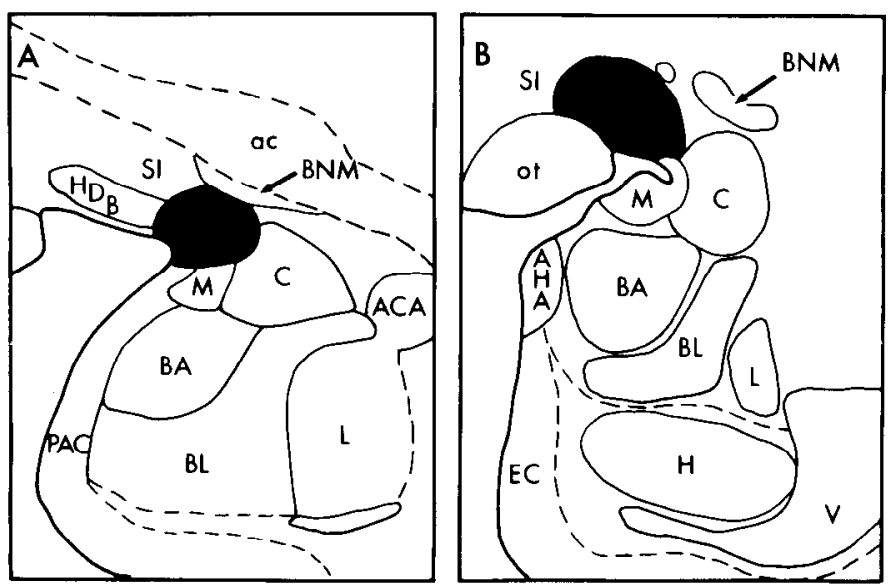

Figure 5. Drawings of representative coronal sections through the amygdala which illustrate the greatest extent of the injection sites in experiments DM18R $(A)$ and DM22R (B). 
(1980). Analysis of a number of injections in essentially all regions of the amygdaloid complex has led us to the conclusion that only the central nucleus of the amygdala sends projections caudal to the midbrain.

\section{Intra-amygdaloid projections}

We shall return, in a subsequent paper, to a more detailed analysis of the intrinsic connections of the primate amygdala. However, we would like to point out, at this time, certain intra-amygdaloid projections which involve the central nucleus.
Injections into either the basolateral (Fig. 6, DM28L) or the basal accessory (Fig. 6, DM29R) nucleus lead to very dense transported label in the central nucleus; in both cases, the label is heaviest over the medial part of the nucleus. After injections of the lateral nucleus (Fig. 6 , DM29L), a similar pattern of labeling is seen in the central nucleus, but the density is substantially less. The central nucleus was also labeled after an injection into the periamygdaloid cortex (Fig. 6, DM12R), and in this case, grains were scattered throughout the nucleus. In all of these cases, some of the transported label may be in

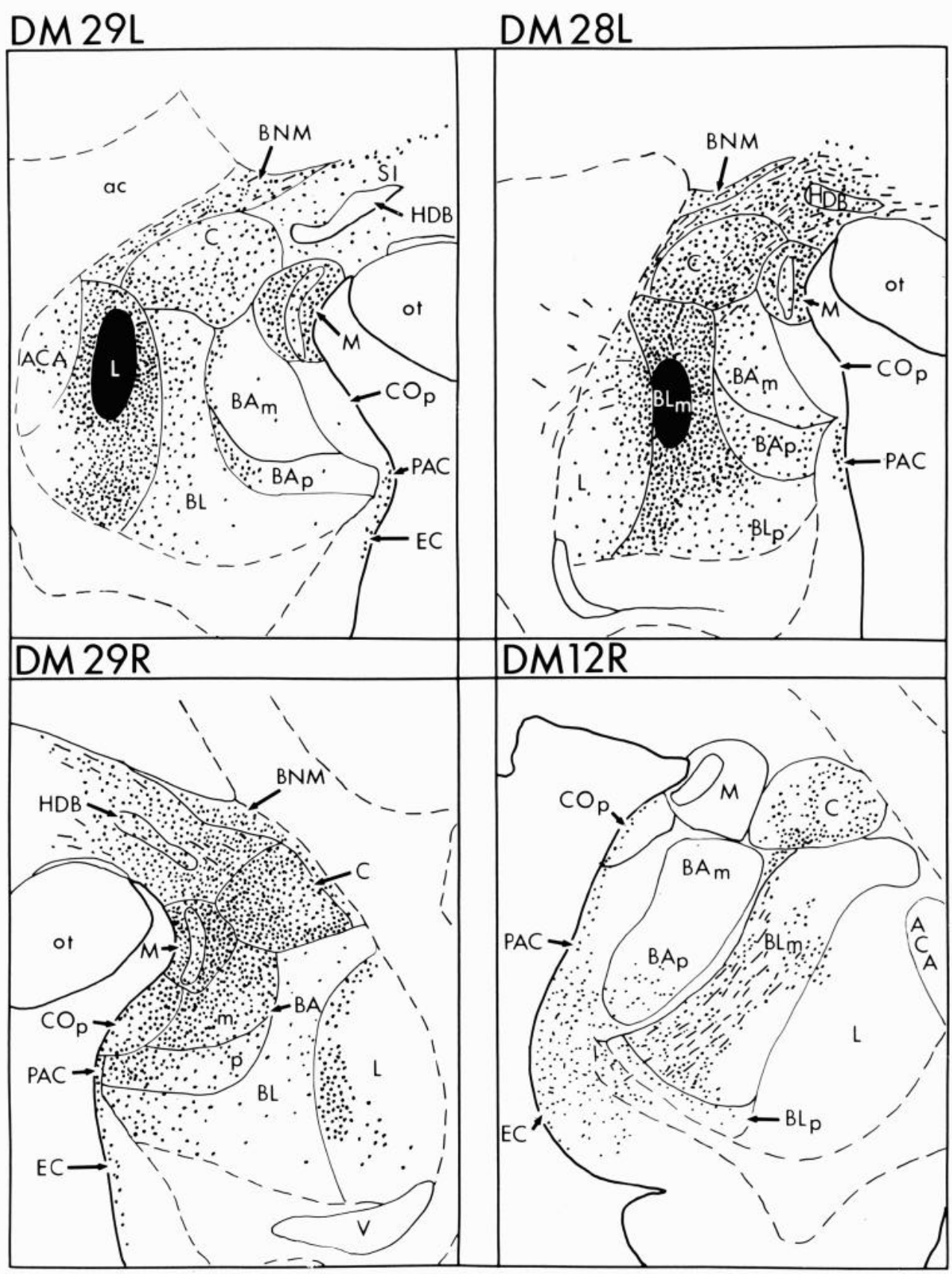

Figure 6. Drawings of representative coronal sections through the amygdala which show intra-amygdaloid terminal labeling after injections of ${ }^{3} \mathrm{H}$-amino-acids which involve the lateral nucleus $(D M 29 L)$, the basolateral nucleus $(D M 28 L)$, the basal accessory nucleus $(D M 29 R)$, and the periamygdaloid cortex $(D M 12 R)$. 
fibers passing through the central nucleus, but most of it appears to be related to fibers which terminate there, because the label is often heavier than in surrounding regions and because labeled fibers of passage appear to run primarily dorsolateral in the fibrous capsule of the central nucleus.

It can be seen in Figure 1 ( $B$ and $C$ ) that the central nucleus itself has a number of intra-amygdaloid projections. The heaviest amygdaloid labeling after a central nucleus injection is over the parvocellular portion of the basolateral nucleus, the periamygdaloid cortex, the cortical nucleus, and caudally, over the amygdalohippocampal area.

\section{Discussion}

The primary finding of the present study is that, among the nuclei of the primate amygdaloid complex, the central nucleus is uniquely capable of influencing a widespread system of brainstem structures ranging from the bed nucleus of the stria terminalis and the hypothalamus rostrally to the dorsal vagal complex and medullary reticular formation caudally. The efferent fibers of the central nucleus follow both the stria terminalis and the ventral amygdalofugal pathways and there appears to be a continuous sheet of fibers which extends between the stria terminalis and the ventral amygdalofugal pathway rostrally and between the dorsal and ventral components of the stria caudally. We have also been able to demonstrate intra-amygdaloid projections from the lateral, basolateral, and basal accessory nuclei and the periamygdaloid cortex to the central nucleus. This finding is of particular interest in light of recent reports which have demonstrated extensive temporal neocortical projections to these areas (Herzog and Van Hoesen, 1976; Turner et al., 1980; Aggleton et al., 1980). Taken together, these data point out a potentially trisynaptic link between temporal association cortices and several autonomic nuclei of the brainstem; we shall discuss this possibility in more detail below as it relates to the functions of the amygdaloid complex.

Prior to 1975 , subcortical amydalofugal projections were thought to extend no further caudally than the posterior hypothalamus. Thus, both Fox (1943) in the cat and Nauta (1961) in the monkey demonstrated a system of fibers which traveled primarily via the ventral amygdalofugal pathway to terminate in the bed nucleus of the stria terminalis, the preoptic region, the lateral hypothalamus, and the thalamus, principally in the mediodorsal nucleus. However, after relatively large pontomedullary injections of horseradish peroxidase (HRP) in rats, cats, and a rhesus monkey, Hopkins (1975) observed retrogradely filled cells located primarily in the central nucleus of the amygdaloid complex with scattered cells in the substantia innominata. More recently, Schwaber et al. (1980) have obtained similar results in the rabbit though with more discrete injections which were largely confined to the vagal complex. In several autoradiographic studies in the rat and cat, injections of $\left[{ }^{3} \mathrm{H}\right]$ leucine which involve the central amygdaloid nucleus have been shown to label projections to several parts of the brainstem, such as the substantia nigra, the mesencephalic and pontine central gray, the parabrachial nuclei, the pontine reticular formation, the dorsal motor nucleus of the vagus, and the nucleus of the solitary tract (Hopkins and Holstege, 1978; Post and Mai, 1980; Krettek and Price, 1978). In the present study, we have been able to demonstrate that the central nucleus of the monkey also projects to all of the nuclei named above and sends fibers as far as the spinomedullary junction. Moreover, the central nucleus projects to a number of basal forebrain, diencephalic, and mesencephalic structures, some of which have not been described previously.

Although many of these projections (e.g., to the midline thalamus and the central gray) were not recognized in a previous study in the rat and cat (Krettek and Price, 1978), re-examination of the earlier material, combined with other, more recent experiments, suggests that most of the projections are also present in those animals. For example, HRP injections into the medial thalamus of the rat have been found to label cells in the central nucleus as well as in the basolateral amygdaluid nucleus (J. L. Price, unpublished observations). Similarly, the fibers which interconnect the ventral and dorsal parts of the stria terminalis are found in the rat but are less readily visualized.

\section{Terminal fields of the central nucleus of the amygdala and their relationship to amygdaloid afferents}

When one compares the distribution of subcortical terminal fields of the primate central nucleus described in this paper with those subcortical areas which have recently been shown to project to the monkey amygdaloid complex by Mehler (1980), Aggleton et al. (1980), and Norita and Kawamura (1980), a striking similarity emerges. In almost all cases, those subcortical nuclei which receive a projection from the central nucleus also send a reciprocal projection back to the amygdaloid complex.

Basal forebrain. As expected from earlier studies of primate amygdaloid projections (Fox, 1943; Nauta, 1961), the central nucleus terminates heavily in the bed nucleus of the stria terminalis. Apparently all components of this nucleus receive a connection, although the fibers are most dense in its lateral aspect as in the rat and cat (Krettek and Price, 1978). Although it is difficult to determine with certainty, it appears that the fibers which innervate the bed nucleus of the stria terminalis and the other basal forebrain regions described below travel both through the stria terminalis and through the most rostral extent of the ventral amygdalofugal pathway. These latter fibers traverse the substantia innominata as they travel medially and some fibers probably terminate in this region. The prominent basal nucleus of Meynert and the nucleus of the horizontal limb of the diagonal band also receive a heavy innervation. A small contingent of fibers travels further medially to end in the medial preoptic region.

Aggleton et al. (1980) observed retrogradely filled cells in the substantia innominata after HRP injections into all portions of the monkey amygdaloid complex; the greatest number of cells were seen after basolateral nucleus injections. These authors do not mention whether a portion of these cells reside in the basal nucleus of Meynert which is embedded in the substantia innominata. The substantia innominata and the basal nucleus 
of Meynert also receive a projection from the midbrain peripeduncular nucleus (Jones et al., 1976) which also projects to the amygdala and, in turn, receives a projection from the central nucleus.

It is of interest that Aggleton et al. (1980) found retrogradely filled cells primarily in the nucleus of the horizontal limb of the diagonal band (which receives a projection from the central nucleus) and few, if any, cells in the vertical limb of the nucleus of the diagonal band (which does not receive fibers from the central nucleus). A few HRP-labeled cells were seen in the preoptic region by Norita and Kawamura (1980) after an injection into the monkey amygdala which involved the lateral and basolateral nuclei.

Hypoth - wirlus. The most prominent projection to the hypothalamus appears to terminate in the lateral hypothalamus, although a few fibers travel medially to the dorsomedial nucleus and more fibers extend caudally into the supramammillary region and posterior hypothalamic area. In the lateral hypothalamic region, a nucleus which we have termed elsewhere the paramammillary nucleus (R. B. Veazey, D. G. Amaral, and W. M. Cowan, submitted for publication) receives the largest innervation. Almost as strikingly, the fibers from the central nucleus almost completely avoid the small lateral tuberal nucleus, although in other experiments, a projection to it has been identified from the hasolateral amygdaloid nucleus (J. L. Price and D. G. Amaral, unpublished observations).

Although Aggleton et al. (1980) observed only a few retrogradely labeled cells in the hypothalamus of the monkey after amygdaloid injections of HRP, both Mehler (1980) and Norita and Kawamura (1980) reported observing a large number of filled cells primarily in the posterior lateral hypothalamus and, if the injection involved the medial, basal accessory, or cortical nuclei, in the ventromedial nucleus. Many fewer cells are seen occasionally in the dorsomedial nucleus, the posterior hypothalamic area, and the supramammillary region. While the central nucleus does not project substantially to the ventromedial hypothalamic nucleus, other amygdaloid nuclei project to the core of the ventromedial nucleus, and the amygdalohippocampal area projects to the shell of the same nucleus (J. L. Price and D. G. Amaral, unpublished observations).

Saper et al. (1976) have described a pathway in the squirrel monkey, which extends from the ventromedial hypothalamic nucleus to several components of the amygdaloid complex, including the shell of the central nucleus. We have observed recently that injections of ${ }^{3} \mathrm{H}$ amino-acids into the monkey posterior lateral hypothalamus which include the paramammillary nucleus also lead to labeling of the central amygdaloid nucleus (R. B. Veazey, D. G. Amaral, and W. M. Cowan, unpublished observations).

Thalamus. The thalamic projection of the central nucleus is directed primarily to midline components of the nucleus centralis, but the ventrolateral portion of nucleus reuniens was labeled also. In the posterior thalamus, the medial pulvinar received a light innervation. There was no labeling over the mediodorsal nucleus after central nucleus injections, but in other preparations with injections either into the lateral, basolateral, or basal acces- sory nuclei, the mediodorsal nucleus received a patchy pattern of innervation primarily into the medial or magnocellular division; in these cases, the nucleus centralis medialis was not labeled.

Mehler (1980), Aggleton et al. (1980), and Norita and Kawamura (1980) all reported HRP-filled cells in the midline thalamic nuclei after injections into the amygdala. All three studies also reported the presence of labeled cells in the nucleus reuniens, particularly in its ventrolateral aspect, a region which Mehler (1980) has chosen to call the nucleus reuniens ventralis. Both Aggleton et al. (1980) and Norita and Kawamura (1980) saw a few labeled cells in the medial division of the pulvinar. Jones and Burton (1976) have demonstrated a projection from the medial pulvinar to the lateral nucleus of the amygdala in monkeys. While, as noted above, we have shown that these regions receive central nucleus projections, it appears that there are a few thalamic exceptions to the general rule of pathway reciprocity. Thus, Mehler (1980) noted HRP-filled cells also in the paraventricular nucleus and in a nucleus located at the medial border of the ventrobasal complex and rostral to the centromedianparafascicular complex which he termed the nucleus interventralis. Aggleton et al. (1980) also observed retrogradely labeled cells in the ventral anterior nucleus, the nucleus rotundus, and the nucleus paracentralis. In addition, Norita and Kawamura (1980) reported filled cells in the centromedian-parafascicular complex and the medial geniculate. It is difficult to determine which of these labeled cells may be due to incidental labeling of adjacent cortical areas.

Mesencephalon. Caudal to the hypothalamus, fibers heavily innervated the substantia nigra pars compacta, the ventral tegmental area, and the peripeduncular nucleus. Projections to these nuclei appear to arise, in part, from the most caudal portions of the ventral amygdalofugal pathway and travel medially around the lateral geniculate nucleus and through the internal capsule. Labeling of the substantia nigra was heaviest in its dorsal part (Olszewski and Baxter's (1954) laminae $\beta$ and $\gamma$ ). As the caudally directed fibers condense in the lateral portion of the tegmental reticular field, some branch off to terminate in the central gray matter, the raphe nuclei (primarily the dorsal nucleus), the cuneiform nucleus, and the nucleus of the posterior commissure.

Mehler (1980), Aggleton et al. (1980), and Norita and Kawamura (1980) noted peroxidase-positive cells in the substantia nigra pars compacta. However, since diaminobenzidine was generally used as the chromagen in these studies and considering the artifactual endogenous peroxidase activity attributed to catecholaminergic cells, the authors were hesitant to attribute the labeling of positive cells to retrograde transport. This problem also affects the interpretation of labeled cells in the locus coeruleus and in the region surrounding the nucleus of the solitary tract. However, it is likely that, in the case of the substantia nigra and the associated ventral tegmental area, there is a sizable projection to the amygdala (Fallon et al., 1978; Fallon and Moore, 1978) which is responsible for the uniquely high levels of dopamine in the central nucleus (Ben-Ari et al., 1975). The peripeduncular nucleus also was labeled retrogradely in each of the primate studies cited above. This nucleus, which straddles the 
dorsolateral border of the substantia nigra and, at its caudal extent, apposes the medial geniculate nucleus was long thought to be related to the auditory system. However, Jones et al. (1976) have shown, in the monkey, that this nucleus projects primarily to the lateral hypothalamus, the substantia innominata and the associated basal nucleus of Meynert, the bed nucleus of the stria terminalis, and the lateral and medial nuclei of the amygdala.

Both Mehler (1980) and Norita and Kawamura (1980) observed retrogradely labeled cells in the raphe nuclei and the majority of these were located in the dorsal raphe nucleus. Autoradiographic studies of the projections of the dorsal raphe nucleus have shown that, in the rat, fibers do enter the amygdala and distribute diffusely mainly to the medial and cortical nuclei (Conrad et al., 1974), while in the cat, a more widespread area of the amygdaloid nucleus, including the central nucleus, appears to receive terminals (Bobillier et al., 1976). We are not aware of any reports which demonstrate projections from the mesencephalic central gray substance to the amygdala.

Pons. As the central nucleus fibers enter the pons, they travel dorsally to terminate heavily in the medial and lateral parabrachial nuclei and, to a lesser extent, in the ventral portion of the locus coeruleus, around the cells of the nucleus subcoeruleus, over the mesencephalic nucleus of the trigeminal nerve, and throughout the lateral portion of the pontine reticular formation. A projection to the more densely packed dorsal portion of the locus coeruleus was not demonstrated directly, but some amygdaloid fibers are found around this nucleus, and these may contact dendrites which extend out from the nucleus (Swanson, 1976).

Mehler (1980) was able to retrogradely label cells only in the lateral parabrachial nucleus, while Norita and Kawamura (1980) saw filled cells in both the medial and lateral parabrachial nuclei after an injection which involved the medial, central, and cortical nuclei; both reports are equivocal as to whether the locus coeruleus sends fibers to the amygdala. The parabrachial nuclei in the rat form part of a region which Norgren (1976) has termed the pontine taste area because of its gustatory inputs from the solitary complex. In an autoradiographic study of the projections of the pontine taste area of the rat, Norgren (1976) reported a heavy innervation of the central nucleus of the amygdala, with few if any fibers going to any other portion of the amygdala. Unfortunately, similar studies have not been carried out in the monkey. Bowden et al. (1978) have reported that the monkey locus coeruleus projects to at least the anterior amygdaloid area and the central nucleus. Certainly in the rat, the central and basolateral nuclei receive a prominent noradrenergic innervation (as identified by dopamine $\beta$-hydroxylase immunohistochemical staining; Swanson and Hartman, 1975) which accounts for the relatively high levels of noradrenaline in these nuclei (Ben-Ari et al., 1975). The cells of origin of this projection are probably located in the locus coeruleus (Ungerstedt, 1971) although this question deserves further study in the primate.

Medulla. Perhaps the most interesting finding in the present study was the very heavy central nucleus inner- vation of the solitary complex and the dorsal motor nucleus of the vagus. This observation confirms previous anterograde and retrograde observations of a similar projection in the rat, rabbit, cat, and monkey (Hopkins, 1975; Hopkins and Holstege, 1978; Post and Mai, 1980; Schwaber et al., 1980). While the projection to the nuclei of the solitary complex is not uniform throughout (the innervation of the rostral half is heavier than that of the caudal half and the parvocellular, dorsomedial region at all levels is the primary terminal field), there appears to be no component of the solitary complex which is totally devoid of input. The predominant labeling of the dorsal motor nucleus of the vagus is to the immediately surrounding area rather than to its core, although there is light label there also; this label overlaps the scattered cells of the A2 catecholaminergic cell group.

In the rat, a direct projection has been demonstrated between the medial portions of the caudal nucleus of the solitary tract and the central nucleus of the amygdala (Ricardo and Koh, 1978). These authors also described projections to the parabrachial nuclei, the hypothalamus, the bed nucleus of the stria terminalis, and the preoptic area. However, available studies suggest that the pattern of efferents of the primate solitary complex is substantially different from that of the rat. The monkey HRP studies cited above did not report filled cells in the solitary complex after amygdaloid injections although there was some equivocation due to the presence of catecholamine-containing cells in the region. Beckstead et al. (1980) recently analyzed the ascending projections of the solitary complex in the monkey using the autoradiographic technique and they were unable to demonstrate any projection to the amygdala. In fact, there were no long projections to the basal forebrain or hypothalamus. Injections of the caudal, non-gustatory regions of the nucleus of the solitary tract led to labeling of the ventrolateral medullary reticular formation, including the area surrounding the nucleus ambiguus, and, as in the rat and cat, of the medial and lateral parabrachial nuclei and adjacent central gray substance. There was little or no labeling of the locus coeruleus. Injections of the rostral, gustatory region of the nucleus showed projections primarily to the parvicellular part of the ventroposteromedial nucleus of the thalamus. There were no projections from the rostral solitary nucleus to the medullary reticular formation or to the parabrachial nuclei.

To summarize then, the central nucleus of the amygdala projects to a number of basal forebrain, diencephalic, mesencephalic, and caudal brainstem structures which, for the most part, reciprocate the connection to some part of the amygdaloid complex. Many of the innervated structures also reciprocate through disynaptic pathways. For example, the peripeduncular nucleus projects directly to the amygdala, but it also innervates the substantia innominata which, in turn, projects to the amygdala. Another example is the nucleus of the solitary tract which, in the rat at least, projects directly to the amygdala but also to the parabrachial nuclei which also send fibers to the amygdala.

The other common characteristic of the projections from the central nucleus to the pons and medulla is that almost all of the areas of termination are either visceral 
afferent or visceromotor centers or themselves project directly to visceromotor structures. Thus, central nucleus fibers terminate not only in the nucleus of the solitary tract and the parabrachial nucleus but also around vagal preganglionic parasympathetic neurons in the dorsal motor nucleus of the vagus and in the reticular formation around the nucleus ambiguus (Nosaka et al., 1979; Geis and Wurster, 1980). The ventral part of the locus coeruleus in the monkey has also been reported to project to parasympathetic neurons in the dorsal motor nucleus and in the sacral spinal cord (Westlund and Coulter, 1980). We have not found direct projections to the sympathetic preganglionic neurons from the central nucleus, but fibers do terminate in several structures which have been reported, in a variety of animals, to have direct projections to the intermediolateral cell column of the thoracic spinal cord, including the perifornical area of the lateral hypothalamus (Saper et al., 1976), the subcoerulear area and the Kölliker-Fuse nucleus in the ventral part of the parabrachial region (Westlund and Coulter, 1980; Saper and Loewy, 1980), the A5 noradrenergic cell group (Loewy et al., 1979), and the lower serotonergic cell groups (B1 and B3) in the raphe magnus and pallidus (Loewy and McKellar, 1981; Martin et al., 1981). From these connections, it would appear that the central nucleus has the potential to exert widespread influence over autonomic or visceral functions. In fact, behavioral and physiological studies of the function of the amygdala predict such a role.

\section{Relationships of the projections of the central nucleus of the amygdala to its possible function}

Electrical stimulation of a variety of loci in the amygdaloid complex of the cat, including the central nucleus, leads initially to an orienting response which is followed either by flight or defense behaviors (Kaada, 1972). There are a number of motoric and autonomic concomitants of this stimulation which include: arrest of spontaneous behavior followed by searching movements, retraction of the nictitating membrane and pupillary dilation, piloerection, micturition, growling, hissing, posturing for attack, elevation of blood pressure with bradycardia, respiratory alterations generally including lower amplitude and increased rate of breathing (some stimulation loci lead to respiratory arrest), alteration of gastric motility and secretion, and masticatory movements with sniffing.

The defense reaction is elicited most easily by stimulation of the basomedial amygdaloid nucleus although the adjoining basolateral nucleus and central nucleus are also positive sites (Hilton and Zbrozyna, 1963). However, there is a column of effective sites for elicitation of the defense reaction or its autonomic correlates which stretches from the amygdala through the hypothalamus and into the pontomedullary brainstem approximately to the level of the dorsal motor nucleus of the vagus nerve. A number of stimulation studies which analyzed the location of these sites (Abrahams et al., 1962, 1970; Coote et al., 1973) have produced topographic maps with a remarkable similarity to the projections of the central nucleus.

Furthermore a number of the nuclei that the central nucleus innervates have been implicated in the ongoing regulation of some of the components of the defense response. For example, Bertrand and Hugelin (1971) consider the medial parabrachial nucleus to be an important component of the respiratory control circuit and von Euler et al. (1976) determined that lesions of the medial parabrachial nucleus cause apneusis by increasing the volume threshold for inspiratory termination. Similarly, Nosaka et al. (1979) have shown, by electrical stimulation, that sites effective for eliciting bradycardia in the caudal brainstem include the dorsal motor nucleus of the vagus, the nucleus of the solitary complex, the nucleus commissuralis, and the area postrema. Both electrophysiological (Stroh-Werz et al., 1977; Ciriello and Calaresu, 1980) and anatomical (Beckstead and Norgren, 1979) studies have demonstrated that the nucleus of the solitary tract and the subjacent reticular formation receive vagal cardiovascular afferents.

In view of these and other connections between the central nucleus and structures which have been implicated in mediation of autonomic responses, it is not unreasonable to suggest that the central nucleus contributes to the organization of the defense reaction by integrating the autonomic components of the behavior. However, the central nucleus is not the only forebrain structure which projects to such a large constellation of brainstem autonomic structures. For example, cells in the paraventricular hypothalamic nucleus and in the perifornical area of the lateral hypothalamus project to virtually all of the same brainstem areas which receive fibers from the central nucleus and also send fibers to the spinal cord (Saper et al., 1976). The central nucleus, however, may be unique in the type of information that it can relay to the brainstem.

As noted previously, the central nucleus does not appear to receive direct neocortical input. Yet, in the present study, we have demonstrated that those components of the amygdaloid complex which do receive afferents from temporal and frontal neocortex (such as the lateral, basolateral, and basal accessory nuclei) project, in turn, upon the central nucleus. It will be of critical importance to identify ultrastructurally the site of termination in the central nucleus of fibers from the other amygdaloid nuclei and also to determine electrophysiologically what synaptic effect they may have. If the temporal association cortex plays some rule in the perception of a fearful situation, then this link through the amygdala may be the route by which appropriate species-specific behaviors and autonomic regulation is mobilized to deal with the situation.

In this light, it is of interest to note that the central nucleus of the amygdala and many of its terminal areas, such as the midline thalamus and the central gray substance, have very high levels of enkephalin (Simatov et al., 1976). In fact, the amygdala itself has the highest level of opiate receptors in the primate brain (Kuhar et al., 1973). There is now evidence in the rat that neurons of at least the central amygdaloid nucleus stain positively with an antibody directed against enkephalin (Uhl et al., 1978). Moreover, efferent fibers of the stria terminalis are also positive for enkephalin-like immunoreactivity. It is thus possible that enkephalin may act as a neuromodu- 
lator in at least some of the projection areas of the central nucleus. On the other hand, several other peptides have been linked to the neurons of the central nucleus. 'T'hus, neurotensin is localized within central nucleus cells (Uhl et al., 1978) and among the fibers of the stria terminalis as is vasoactive intestinal polypeptide (Roberts et al., 1980).

Recently, the amygdala has been shown to play a role in the processing of long term memory in primates (Mishkin, 1978), apparently in concert with the hippocampal formation. Kapp et al. (1979) have shown in the rabbit that selective lesions of the central nucleus of the amygdala produced a marked deficit in the learning of a cardiac deceleratory conditioned response to an aversive stimulus. One wonders what effect the inability to produce an appropriate ensemble of autonomic responses to a novel stimulus might have on learning in the primate.

\section{References}

Abrahams, V. C., S. M. Hilton, and J. L. Malcolm (1962) Sensory connections to the hypothalamus and midbrain, and their role in the reflex activation of the defence reaction. $J$. Physiol. (Lond.) 164: 1-16.

Abrahams, V. C., S. M. Hilton, and A. Zbrozyna (1970) Active muscle vasodilation produced by stimulation of the brain stem: Its significance in the defence reaction. J. Physiol. (Lond.) 154: 491-513.

Aggleton, J. P., M. J. Burton, and R. E. Passingham (1980) Cortical and subcortical afferents to the amygdala of the rhesus monkey (Macaca mulatta). Brain Res. 190: 347-368.

Beckstead, R. M., and R. Norgren (1979) An autoradiographic examination of central distribution of the trigeminal, facial, glossopharyngeal, and vagal nerves in the monkey. J. Comp. Neurol. 184: 455-472.

Beckstead, R. M., J. R. Morse, and R. Norgren (1980) The nucleus of the solitary tract in the monkey: Projections to the thalamus and brain stem nuclei. J. Comp. Neurol. 190: 259-282.

Ben-Ari, Y., R. E. Zigmond, and K. F. Moore (1975) Regional distribution of tyrosine hydroxylase, norepinephrine and dopamine within the amygdaloid complex of the rat. Brain Res. 87: $96-101$.

Betrand, F., and A. Hugelin (1971) Respiratory synchronizing function of nucleus parabrachialis medialis: Pneumotaxic mechanisms. J. Neurophysiol. 34: 189-207.

Bobillier, P., S. Sequin, F. Petitjean, D. Salvert, M. Touret, and M. Jouvet (1976) The raphe nuclei atlas of the cat brain stem: A topographical atlas of their efferent projections as revealed by autoradiography. Brain Res. 113: 449-486.

Bogerts, B. (1981) A brainstem atlas of catecholaminergic neurons in man, using melanin as a natural marker. J. Comp. Neurol. 197: 63-80.

Bowden, D. M., D. C. German, and W. D. Poynter (1978) An autoradiographic, semistereotaxic mapping of major projections from locus coeruleus and adjacent nuclei in Macaca mulatta. Brain Res. 145: 257-276.

Ciriello, J., and F. R. Calaresu (1980) Monosynaptic pathway from cardiovascular neurons in the nucleus tractus solitarii to the paraventricular nucleus in the cat. Brain Res. 193: 529-533.

Conrad, L. C. A., C. M. Leonard, and D. W. Pfaff (1974) Connections of the median and dorsal raphe nuclei in the rat: An autoradiographic and degeneration study. J. Comp. Neurol. 156: 179-206.

Coote, J. H., S. M. Hilton, and A. W. Zbrozyna (1973) The ponto-medullary area integrating the defence reaction in the cat and its influence on muscle blood flow. J. Physiol. (Lond.) 229: 257-274.

Cowan, W. M., G. Raisman, and T. P. S. Powell (1965) The connexions of the amygdala. J. Neurol. Neurosurg. Psychiatry 28: 137-151.

Cowan, W. M., D. I. Gottlieb, A. E. Hendrickson, J. L. Price, and T. A. Woolsey (1972) The autoradiographic demonstration of axonal connections in the central nervous system. Brain Res. .37: 21-55.

de Olmos, J. S. (1972) The amygdaloid projection field in the rat as studied with the cupric-silver method. In The Neurobiology of the Amygdala, B. E. Eleftheriou, ed., pp. 295-317, Plenum Press, New York.

Fallon, J. H., and R. Y. Moore (1978) Catecholamine innervation of the basal forebrain. IV. Topography of the dopamine projection to the basal forebrain and neostriatum. J. Comp. Neurol. 180: 545-580.

Fallon, J. H., D. A. Koziell, and R. Y. Moore (1978) Catecholamine innervation of the basal forebrain. II. Amygdala, suprarhinal cortex and entorhinal cortex. J. Comp. Neurol. 180: 509-532.

Felten, D. L., A. M. Laties, and M. B. Carpenter (1974) Monoamine-containing cell bodies in the squirrel monkey brain. Am. J. Anat. 139: 153-166.

Fox, C. A. (1943) The stria terminalis, longitudinal association bundle and precommissural fornix fibers in the cat. J. Comp. Neurol. 79: 277-295.

Garver, D. L., and J. R. Sladek (1975) Monoamine distribution in primate brain. I. Catecholamine-containing perikarya in the brain stem of Macaca speciosa. J. Comp. Neurol. 159: 289-304.

Geis, G. S., and R. D. Wurster (1980) Horseradish peroxidase localization of cardiac vagal preganglionic somata. Brain Res. 182: $19-30$.

German, D. C., and D. M. Bowden (1975) Locus coeruleus in rhesus monkey (Macaca mulatta): A combined histochemical fluorescence, Nissl and silver study. J. Comp. Neurol. 161: 19-29.

Heimer, L., and W. J. H. Nauta (1969) The hypothalamic distribution of the stria terminalis in the rat. Brain Res. 13: 139-159.

Herzog, A. G., and G. W. Van Hoesen (1976) Temporal neocortical afferent connections to the amygdala in the rhesus monkey. Brain Res. 115: 57-69.

Hilton, S. M., and A. W. Zbrozyna (1963) Amygdaloid region for defence reactions and its efferent pathway to the brain stem. J. Physiol. (Lond.) 165: 106-173.

Hopkins; D. A. (1975) Amygdalotegmental projections in the rat, cat and monkey. Neurosci. Lett. 1: 263-270.

Hopkins, D. A., and G. Holstege (1978) Amygdaloid projections to the mesencephalon, pons and medulla oblongata in the cat. Exp. Brain Res. 32: 529-547.

Jones, E. G., and H. Burton (1976) A projection from the medial pulvinar to the amygdala in primates. Brain Res. 104: 142147.

Jones, E. G., H. Burton, C. B. Saper, and L. W. Swanson (1976) Midbrain, diencephalic and cortical relationships of the basal nucleus of Meynert and associated structures in primates. J. Comp. Neurol. 167: 385-420.

Kaada, B. R. (1972) Stimulation and regional ablation of the amygdaloid complex with reference to functional representations. In The Neurobiology of the Amygdala, B. E. Eleftheriou, ed., pp. 205-282, Plenum Press, New York.

Kapp, B. S., R. C. Frysinger, M. Gallagher, and J. R. Haseton (1979) Amygdala central nucleus lesions: Effect on heart rate and conditioning in the rabbit. Physiol. Behav. 23: 1109-1117.

Krettek, J. E., and J. L. Price (1978) Amygdaloid projections to subcortical structures within the basal forebrain in the rat and cat. J. Comp. Neurol. 178: 225-254. 
Kuhar, M. J., C. B. Pert, and S. H. Snyder (1973) Regional distribution of opiate receptor binding in monkey and human brain. Nature 245: 447-450.

Loewy, A. D., and S. McKellar (1981) Serotonergic projections from the ventral medulla to the intermediolateral cell column in the rat. Brain Res. 216: 146-152.

Loewy, A. D., S. McKellar, and C. B. Saper (1979) Direct projections from the A5 catecholamine cell group to the intermediolateral cell column. Brain Res 174: 309-314.

Martin, G. F., T. Cabana, A. O. Humbertson, Jr., L. C. Laxton, and W. M. Panneton (1981) Spinal projections from the medullary reticular formation of the North American opossum: Evidence for connectional heterogeneity. J. Comp. Neurol. 196: 663-682.

Mehler, W. R. (1980) Subcortical afferent connections of the amygdala in the monkey. J. Comp. Neurol. 190: 733-762.

Mishkin, M. (1978) Memory in monkeys severely impaired by combined but not by separate removal of amygdala and hippocampus. Nature 273: 297-298.

Nauta, W. J. H. (1961) Fibre degeneration following lesions of the amygdaloid complex in the monkey. J. Anat. 95: 515-532.

Norgren, R. (1976) Taste pathways to hypothalamus and amygdala. J. Comp. Neurol. 166: 17-30.

Norita, M., and K. Kawamura (1980) Subcortical afferents to the monkey amygdala: An HRP study. Brain Res. 190: 225230.

Nosaka, S., T. Yamamoto, and K. Yasunaga (1979) Localization of vagal cardioinhibitory preganglionic neurons within rat brain stem. J. Comp. Neurol. 186: 79-92.

Olszewski, J. (1952) The Thalamus of the Macaca mulatta. An Atlas for Use with the Stereotaxic Instrument, S. Karger, Basel, Switzerland.

Olszewski, J., and D. Baxter (1954) Cytoarchitecture of the Human Brain Stem, J. P. Lippincott, Philadelphia.

Post, S., and J. K. Mai (1980) Contribution to the amygdaloid projection field in the rat. A quantitative autoradiographic study. J. Hirnforsch. 21: 199-225.

Ricardo, J. A., and E. T. Koh (1978) Anatomical evidence of direct projections from the nucleus of the solitary tract to the hypothalamus, amygdala and other forebrain structures in the rat. Brain Res. 153: 1-26.

Roberts, G. W., P. L. Woodhams, M. G. Bryant, T. J. Crow, S. R. Bloom, and J. M. Polak (1980) VIP in the rat brain: Evidence for a major pathway linking the amygdala and hypothalamus via the stria terminalis. Histochemistry 65 : 103-119.
Saper, C. B., and A. D. Loewy (1980) Efferent connections of the parabrachial nucleus in the rat. Brain Res. 197: 291-317.

Saper, C. B., A. D. Loewy, L. W. Swanson, and W. M. Cowan (1976) Direct hypothalamo-autonomic connections. Brain Res. 117: 305-312.

Schofield, S. P. M., and B. J. Everitt (1981) The organization of indoleamine neurons in the brain of the rhesus monkey (Macaca mulatta). J. Comp. Neurol. 197: 369-383.

Schwaber, J. S., B. S. Kapp, and G. Higgens (1980) The origin and extent of direct amygdala projections to the region of the dorsal motor nucleus of the vagus and the nucleus of the solitary tract. Neurosci Lett. 20: 15-20.

Simantov, R., M. J. Kuhar, G. W. Pasternak, and S. H. Snyder (1976) The regional distribution of a morphine-like factor enkephalin in monkey brain. Brain Res. 106: 189-197.

Stroh-Werz, M., P. Langhorst, and H. Camerer (1977) Neuronal activity with cardiac rhythm in the nucleus of the solitary tract in cats and dog. I. Different discharge patterns related to the cardiac cycle. Brain Res. 133: 65-80.

Swanson, L. W. (1976) 'The locus coeruleus: A cytoarchitectonic, Golgi and immunohistochemical study in the albino rat. Brain Res. 110: 39-56.

Swanson, L. W., and B. K. Hartman (1975) The central adrenergic system. An immunofluorescence study of the location of cell bodies and their efferent connections in the rat utilizing dopamine- $\beta$-hydroxylase. J. Comp. Neurol. 163: 467-506.

Turner, B. H., M. Mishkin, and M. Knapp (1980) Organization of the amygdalopetal projections from modality-specific cortical association areas in the monkey. J. Comp. Neurol. 191: $515-543$.

Uhl, G. R., R. R. Goodman, M. J. Kuhar, and S. H. Snyder (1978) Enkephalin and neurotensin: Immunohistochemical localization and identification of an amygdalofugal pathway. Adv. Biochem. Psychopharmacol. 18: 71-87.

Ungerstedt, U. (1971) Stereotaxic mapping of the monoamine pathways in the rat brain. Acta Physiol. Scand. 367: 1-48.

von Euler, C., I. Marttila, J. E. Remmers, and J. Trippenbach (1976) Effects of lesions in the parabrachial nucleus on the mechanisms for central and reflex termination of inspiration in the cat. Acta Physiol. Scand. 96: 324-337.

Westlund, K. D., and J. D. Coulter (1980) Descending projections of the locus coeruleus and subcoeruleus/medial parabrachial nuclei in the monkey: Axonal transport studies and dopamine- $\beta$-hydroxylase immunocytochemistry. Brain Res. Rev. 2: 235-264. 